\title{
$A$ agenda atual da Reforma Sanitária Brasileira
}

\section{| ' Luis Eugênio Portela Fernandes de Souza |}

1 Programa de Economia, Tecnologia e Inovação em Saúde do Instituto de Saúde Coletiva, Universidade Federal da Bahia. Presidente da Associação Brasileira de Saúde Coletiva (ABRASCO). Salvador-BA, Brasil.

A saúde foi um tema importante nas eleições de 2014. Todas candidaturas à presidência da República incluíram em seus programas de campanha múltiplas referências ao tema. De um lado, enalteciam o Sistema Único de Saúde (SUS) como uma grande política social e, de outro, prometiam a expansão e a qualificação dos serviços de saúde.

Embora apresentadas de modo sucinto, típico de programas eleitorais, as proposições não destoaram das que têm sido defendidas pelo Conselho Nacional de Saúde e por organizações da sociedade civil que têm as políticas de saúde como foco de interesse.

Dentre essas organizações, um conjunto de oito entidades - Associação Brasileira de Saúde Coletiva, Associação Brasileira de Economia da Saúde, Associação Brasileira Rede Unida, Associação Paulista de Saúde Pública, Associação de Membros do Ministério Público em Defesa da Saúde, Centro Brasileiro de Estudos de Saúde, Instituto de Direito Sanitário Aplicado e Sociedade Brasileira de Bioética -- constituiu um Fórum da Reforma Sanitária Brasileira para discutir uma Agenda da Saúde para as eleições e o próximo período governamental.

Uma possível estruturação dessa Agenda em cinco eixos (desenvolvimento, democracia, modelo de atenção à saúde, gestão e financiamento) é apresentada a seguir como forma de convite ao debate para os pesquisadores da Saúde Coletiva, em geral, e os leitores da Physis, em especial. 


\section{Desenvolvimento}

Diferentemente de crescimento econômico, só há desenvolvimento quando o progresso técnico, os ganhos de produtividade e o aumento da riqueza são acompanhados da melhoria geral das condições de vida. Assim, a melhoria da saúde, como parte das condições de vida, é elemento constitutivo do desenvolvimento.

Desde os anos 1970, o movimento da Reforma Sanitária tem afirmado que a pobreza e a desigualdade social são obstáculos a uma boa situação de saúde. Por isso hoje, como antes, é preciso articular um projeto nacional de desenvolvimento que seja promotor da saúde em suas dimensões individual e coletiva.

Assim, se pretende priorizar a saúde, o próximo governo deve coordenar a construção de um modelo de desenvolvimento baseado na soberania nacional; na promoção do pleno emprego e no combate às desigualdades de renda; nos investimentos em habitação, saneamento e transporte público; na ampliação da participação relativa do emprego industrial em segmentos de alto valor agregado; no manejo sustentável dos recursos naturais; e no acesso universal a serviços de qualidade nas áreas de Seguridade Social, Educação e Segurança Alimentar (CARDOSO JR, 2012; FAGNANI, 2014).

\section{Democracia}

Apesar de avanços significativos no exercício da democracia nas últimas décadas, a sociedade brasileira continua a apresentar um forte deficit democrático, expresso na percepção generalizada de que as elites políticas não representam os anseios do povo e na persistência de graves desigualdades sociais.

A superação desse duplo deficit passa pelo fortalecimento da participação popular nas decisóes da República, de modo a fazer com que todos sejam contemplados pelos resultados das políticas. Nesse sentido, um governo comprometido com a saúde deve buscar a efetivação dos mecanismos de participação direta previstos na Constituição, como a criação da iniciativa popular de plebiscitos e referendos, a realização de plebiscito sobre as políticas econômicas e sociais, a obrigatoriedade de referendo de quaisquer leis em matéria eleitoral e a preferência na tramitação de projetos de lei de iniciativa popular, entre outros (COMPARATO, 2004). Deve ainda, no âmbito do Poder Executivo, fortalecer o Sistema Nacional de Participação Social, qualificando a atuação dos Conselhos, de modo que neles esteja representada a diversidade social do 
país, que os representantes mantenham relações estreitas com suas bases e que os debates nas instâncias participativas tenham repercussões nas políticas oficiais.

Precisa também se comprometer com a democratização do Poder Judiciário, empenhando-se, sobretudo, na exigência de fundamentação argumentativa para todas as sentenças judiciais, além do fim do privilégio de foro para as altas autoridades da República (MATTOS; BOLLMANN, 2012).

Por fim, um governo comprometido com a saúde tem que assegurar o caráter público da comunicação social, promovendo a regulação democrática: (a) do sistema de comunicações; (b) da propriedade dos meios de comunicação; e (c) dos conteúdos veiculados.

\section{Modelo de atenção à saúde}

A implantação de um sistema capaz de oferecer cuidado integral à saúde exige a superação do modelo biomédico e mercantilista de atenção à saúde, predominante no Brasil. Para avançar nesse sentido, há que se fortalecer as políticas de promoção da saúde, articulando iniciativas intersetoriais dirigidas aos determinantes sociais da saúde, sem descuidar das ações de prevenção, diagnóstico e tratamento de doenças e agravos.

A constituição de redes de atenção à saúde é, provavelmente, a principal estratégia para operacionalizar o cuidado integral. As redes têm sido objeto de várias medidas normativas, desde a NOAS n ${ }^{\circ} 1 / 2001$ até o Decreto no 7.508/2011, que produziram avanços pontuais, mas não tiveram êxito em larga escala. Certamente, as limitações do financiamento e dos mecanismos de coordenação federativa são causas centrais da dificuldade de operacionalização das redes.

A integração em rede dos serviços de saúde, contudo, não é suficiente para mudar o modelo de atenção. É também necessário modificar a dinâmica econômica que sustenta o modelo biomédico mercantilista. Tal dinâmica, determinada pelo poder das grandes empresas de medicamentos, equipamentos e material médico-hospitalar, precisa ser substituída por outra que seja orientada pelos objetivos das políticas de saúde. Vale registrar que, desde 2004, esforços nesse sentido têm sido feitos pelo Governo Federal, com resultados positivos.

Enfim, um governo comprometido com a saúde vai preservar e aprimorar as iniciativas de articulação das políticas de saúde, de ciência e tecnologia e de indústria e comércio para promover o desenvolvimento e a produção nacional, 
a custos suportáveis pelo SUS, das tecnologias e dos insumos indispensáveis ao atendimento das necessidades de saúde de todos.

\section{Gestão}

Um governo será comprometido com a saúde se enfrentar três problemas graves de gestão: o burocratismo, a insuficiência de coordenação federativa e a falta de uma política de pessoal da saúde.

Para superar o burocratismo, é fundamental profissionalizar a gestão, valorizando as carreiras públicas e adotando critérios de desempenho para avaliar e premiar a eficácia e a eficiência (ABRUCIO, 2007).

Quanto à coordenação federativa, deve-se lembrar que o SUS foi concebido como um sistema regionalizado e hierarquizado. Na prática, todavia, não tem sido possível organizá-lo assim, mas tem predominado a "municipalização autárquica” (MENDES, 2001).

A organização de regiōes, de acordo com as identidades territoriais e com adequadas escalas populacionais, é a melhor estratégia para promover a coordenação das políticas sociais em um país federado. E para que se organizem as regiōes, é impositiva a constituição de instâncias de poder compartilhado entre os municípios de uma região, o respectivo estado e a Uniāo, todos envolvidos no financiamento e na condução das açôes governamentais.

No que se refere à política de pessoal em saúde, há que se admitir que, sob o SUS, pouco se avançou (PIERANTONI e cols., 2008). Com efeito, o desafio ainda é formular e implantar uma política nacional de gestão do trabalho e da educação em saúde. Essa política, no que toca à educação, deve ter como objetivos centrais ampliar o quantitativo de profissionais formados e adequar seus perfis às necessidades de saúde da população. Para tanto, toda a rede de serviços deve se tornar espaço de formação, o que viabiliza também as práticas de educação permanente.

No que toca à gestão do trabalho, o provimento e a distribuição dos profissionais de saúde devem estar baseados no dimensionamento da necessidade de pessoal, em termos quantitativos e qualitativos, a partir das necessidades de saúde, em um processo contínuo de planejamento concertado entre as três esferas de governo. Além disso, a garantia de condições apropriadas de trabalho passa pela revisão do atual sistema de regulação profissional, excessivamente marcado pela defesa dos interesses corporativos. 
Por fim, um governo efetivamente comprometido com a saúde vai ampliar o investimento no SUS. No curto prazo, vai defender a aprovação no Congresso Nacional do Projeto de Lei de Iniciativa Popular, que obriga a União a destinar, no mínimo, $10 \%$ das suas receitas correntes brutas para a saúde. E, de forma estruturante, vai consolidar o orçamento da Seguridade Social, definindo fontes estáveis e suficientes de recursos. Além disso, vai acabar com a desvinculação das receitas da União (DRU) e rever a política de desoneração fiscal, que têm retirado recursos da Seguridade Social.

Esse governo vai ainda buscar a extinção progressiva dos subsídios, dos incentivos tributários e das isenções fiscais para o setor privado da saúde. Ademais, vai assegurar a efetiva regulação dos prestadores privados sem contratos ou convênios com o SUS, nos limites de sua atuação como comerciantes de serviços de saúde.

\section{Referências}

ABRUCIO, F.L. Trajetória recente da gestão pública brasileira: um balanço crítico e a renovação da agenda de reformas. Revista de Administração Pública (RAP). Rio de Janeiro. Edição Especial Comemorativa, 2007, p. 67-86.

CARDOSO JR, C. Desenvolvimento como eixo e os eixos para o desenvolvimento. In: FUNDAÇÃO OSWALDO CRUZ. A saúde no Brasil em 2030: diretrizes para a prospecção estratégica do sistema de saúde brasileiro. Rio de Janeiro: Fiocruz, 2012, p. 25-37.

COMPARATO, F.K. Viva o povo brasileiro! Folha de S. Paulo, seção Opinião, em 15 nov. 2004. Disponível em: <http://wwwl.folha.uol.com.br/fsp/opiniao/fz1511200409.htm>.

FAGNANI, E. Fragmentação da luta politica e agenda de desenvolvimento: notas e provocaçōes para impulsionar o debate. Texto para discussão. Campinas: Plataforma Social, 2014.

MATTOS, F.C.B. de; BOLLMANN, V. Propostas para aprimorar a democratização do Judiciário. Revista Consultor Jurídico, 27 dez. 2012. Disponível em: <http://www.conjur. com.br/2012-dez-27/propostas-aprimorar-democratizacao-poder-judiciario>

MENDES, E.V. Os grandes dilemas do SUS. Vol. I. Salvador: Casa da Qualidade, 2001.

PIERANTONI, C.R. et al. Gestão do trabalho e da educação em saúde: recursos humanos em duas décadas do SUS. Physis: revista de saúde Coletiva. Rio de Janeiro, v. 18, n. 4, p. 685-704, 2008. 